\title{
Electronically-Controlled Current-Mode Second Order Sinusoidal Oscillators Using MO-OTAs and Grounded Capacitors
}

\author{
Data Ram Bhaskar ${ }^{1}$, Kasim Karam Abdalla ${ }^{1}$, Raj Senani ${ }^{2}$ \\ ${ }^{1}$ Department of Electronics and Communication Engineering, Faculty of Engineering and Technology, \\ Jamia Millia Islmia, New Delhi, India \\ ${ }^{2}$ Division of Electronics and Communication Engineering, Netaji Subhas Institute of Technology, Delhi, India \\ E-mail: senani@nsit.ac.in
}

Received December 17, 2010; revised February 9, 2011; accepted February 21, 2011

\begin{abstract}
Five new electronically-controllable second order current-mode sinusoidal oscillators using three multioutput operational transconductance amplifiers (MO-OTAs) and two grounded capacitors (GC) have been presented. Simulation results are included to confirm the theoretical analysis based upon CMOS OTAs implementable in $0.5 \mu \mathrm{m}$ technology.
\end{abstract}

Keywords: Oscillators, Analog Electronics, Current Mode Circuits, Operational Transconductance Amplifiers

\section{Introduction}

Recently, Tsukutani, Sumi and Fukui [1] presented two current-mode OTA-C sinusoidal oscillators each of which employs three MO-OTAs and three grounded capacitors (GC) and provides three explicit current outputs. However, whereas one of the circuits of [1] does not have independent controllability of the condition of oscillation (CO) and the frequency of oscillation (FO) through different transconductances (which is not only a desirable but also an expected property which one likes to see in any OTA-C oscillator), on the other hand, both the circuits employ three GCs and hence, are not canonic.

The main objective of this paper is to present five new current-mode electronically-controllable second order sinusoidal oscillators which use only three MO-OTAs like the circuits of [1] but in contrast to the circuits of [1], the proposed circuits use no more than two GCs and are capable of providing a non-interacting and independent control of both $\mathrm{CO}$ and $\mathrm{FO}$ and in addition also provide quadrature outputs which find numerous applications (for instance, in communications for quadrature mixers and single-sideband generators and in instrumentation for vector generator or selective voltmeters [2] etc.).

\section{The Proposed Circuits}

The proposed circuits are shown in Figure 1. For an ideal MO-OTA with transconductance $g_{m}$, the current output $I_{o}$ is given by $I_{o}=g_{m}\left(V_{+}-V_{-}\right)$, where $V_{+}$and $V_{-}$ are the input voltages at non-inverting input terminal and inverting input terminal respectively. Routine analysis yields, the condition of oscillation (CO) and the frequency of oscillation (FO) for all circuits as summarized in Table 1, which also shows the relevant modes of availability of quadrature outputs in all cases. From the expressions of FO given in Table 1, it can be easily deduced that magnitude of all active and passive sensitivities of FO, in all the five circuits, would be in the range of 0 to $1 / 2$ and circuits thus, enjoy low sensitivity properties.

\section{Simulation Results}

To verify the validity of the proposed configurations, circuit simulation of the oscillators has been carried out using the CMOS MO-OTA circuit from [1] (presented here as Figure 2). In PSPICE simulation, implementation was based upon a CMOS OTA in $0.5 \mu \mathrm{m}$ technology. The aspect ratios of the MOSFETs were taken as shown in Table 2. The CMOS OTAs were biased with DC power supply voltages $V_{D D}=+2.5 \mathrm{~V}, V_{S S}=-2.5 \mathrm{~V}$. The generated waveforms, transient and the frequency spectrum for the proposed circuits obtained from simulations are shown in Figure 3, Figure 4 and Figure 5, 


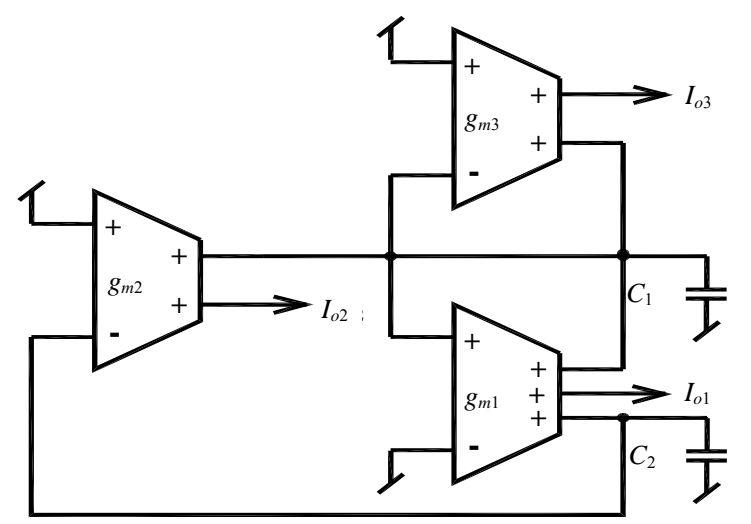

(1)

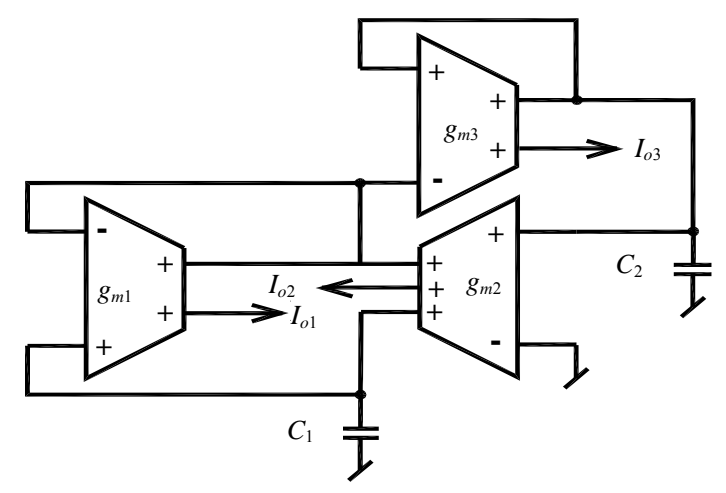

(2)

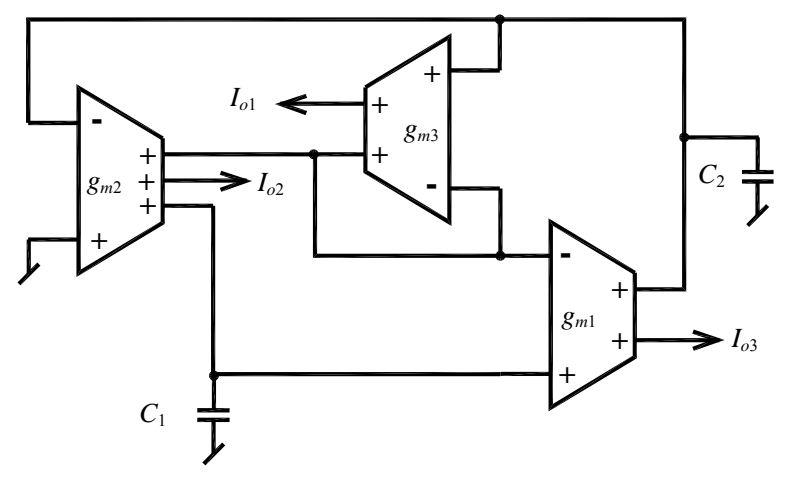

(3)

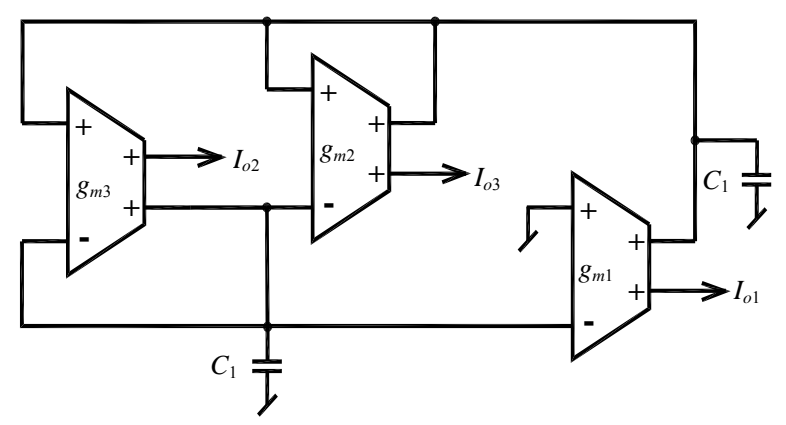

(4)

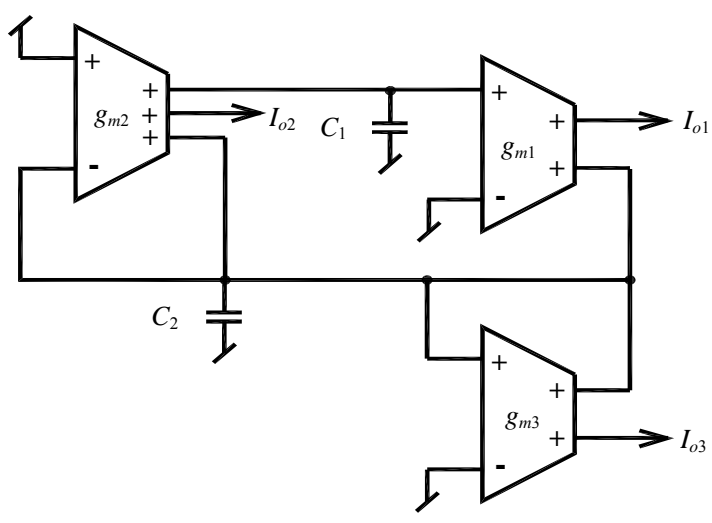

(5)

Figure 1. Proposed configurations.

respectively. The element values used in the simulations along with the theoretical and practical output frequency and total harmonic distortions (THD) for the proposed circuits are summarized in Table 3. All the proposed oscillators have been checked for robustness using Monte-Carlo simulations, however, to conserve space, a sample result has been shown in Figure 6 for the oscillator (5) of Figure 1, which confirms that for $\pm 15 \%$ variations in the value of $g_{m 3}$, the value of oscillation frequency remains close to its normal value of $1.1996 \mathrm{MHz}$ and hence almost unaffected by change in $g_{m 3}$ (which should be the case since $g_{m 3}$ does not feature in the expression of $\mathrm{FO}$ ).

In all cases, a very good correspondence between designed values and those observed from PSPICE simulations has been obtained. The simulation results, thus, confirm the workability of the proposed configurations.

\section{Comparison with Other Previously Known OTA-Based Oscillators}

It is now useful to compare the proposed new circuits with some of the earlier proposed OTA-based oscillators. Recently, Kamat, Anand Mohan and Prabhu [3] presented a quadrature oscillator employing two MO-OTAs, two single output OTAs and two GCs. The circuit does not have independent controllability of $\mathrm{CO}$ and FO. It may also be recalled in this context that much earlier, in reference [4], two minimum-component electronically-tunable sinusoidal oscillators using two OTAs and two GCs had been presented however, these circuits too did not have independent controllability of $\mathrm{CO}$ and FO. Furthermore, there is another class of OTA-based RC oscillators known earlier [5-9] which employ one or two OTAs along with a number of resistors and two capacitors. However, when these OTA-RC oscillators from [5-9] can be transformed into OTA-C oscillators, by simulating the resistors with OTAs, the resulting entirely-OTA-based oscillators will 


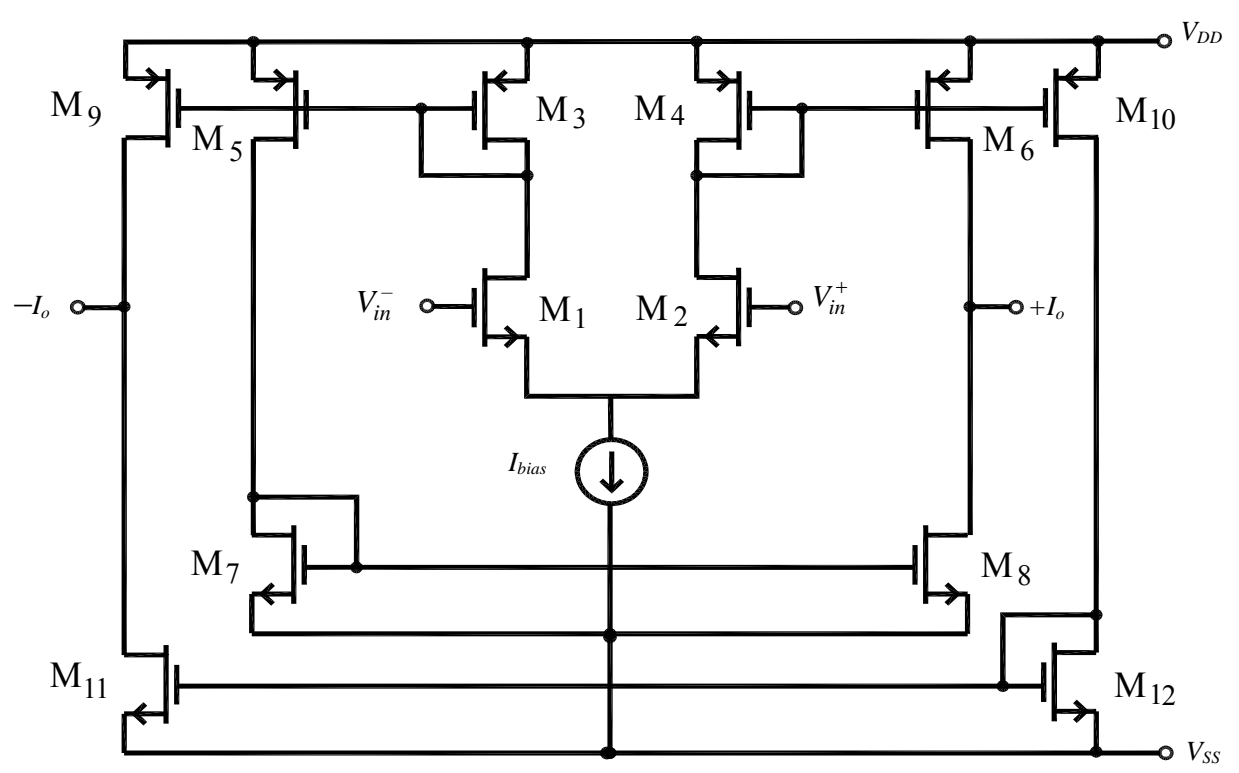

Figure 2. MO-OTA.

Table 1. Condition of oscillation and frequency of oscillation for the proposed circuits.

\begin{tabular}{cccc}
$\begin{array}{c}\text { Circuit } \\
\text { No. }\end{array}$ & $\begin{array}{c}\text { Condition of } \\
\text { Oscillation (CO) }\end{array}$ & $\begin{array}{c}\text { Frequency of } \\
\text { Oscillation (FO) }\end{array}$ & $\begin{array}{c}\text { Availability of } \\
\text { Quadrature Outputs }\end{array}$ \\
\hline 1 & $\left(g_{m 3}-g_{m 1}\right) \leq 0$ & $\frac{1}{2 \pi} \sqrt{\frac{g_{m 1} g_{m 2}}{C_{1} C_{2}}}$ & $\frac{I_{o 2}(s)}{I_{o 1}(s)}=\frac{-g_{m 2}}{s C_{2}}, \frac{I_{o 2}(s)}{I_{o 3}(s)}=\frac{g_{m 1} g_{m 2}}{g_{m 3} s C_{2}}$ \\
2 & $\left(g_{m 2}-g_{m 1}\right) \leq 0$ & $\frac{1}{2 \pi} \sqrt{\frac{g_{m 2} g_{m 3}}{C_{1} C_{2}}}$ & $\frac{I_{o 3}(s)}{I_{o 1}(s)}=\frac{g_{m 3}}{s C_{1}}, \frac{I_{o 3}(s)}{I_{o 2}(s)}=\frac{-g_{m 3}}{s C_{1}} \quad$ for $g_{m 1}=g_{m 2}$ \\
3 & $\left(g_{m 1}-g_{m 2}\right) \leq 0$ & $\frac{1}{2 \pi} \sqrt{\frac{g_{m 2} g_{m 3}}{C_{1} C_{2}}}$ & $\frac{I_{o 3}(s)}{I_{o 1}(s)}=\frac{-g_{m 3}}{s C_{1}}, \frac{I_{o 3}(s)}{I_{o 2}(s)}=\frac{g_{m 3}}{s C_{1}} \quad$ for $g_{m 1}=g_{m 2}$ \\
4 & $\left(C_{2} g_{m 3}-C_{1} g_{m 1}\right) \leq 0$ & $\frac{1}{2 \pi} \sqrt{\frac{g_{m 1} g_{m 2}}{C_{1} C_{2}}}$ & $\frac{I_{o 1}(s)}{I_{o 2}(s)}=\frac{-g_{m 1}}{s C_{1}}$ \\
5 & $\left(g_{m 2}-g_{m 3}\right) \leq 0$ & $\frac{1}{2 \pi} \sqrt{\frac{g_{m 1} g_{m 2}}{C_{1} C_{2}}}$ & $\frac{I_{o 1}(s)}{I_{o 3}(s)}=\frac{g_{m 2} g_{m 1}}{g_{m 3} s C_{1}}, \frac{I_{o 1}(s)}{I_{o 2}(s)}=\frac{-g_{m 1}}{s C_{1}}$
\end{tabular}

Table 2. Aspect ratios of MOSFETs used in the MO-OTA implementation.

\begin{tabular}{ccc}
\hline MOSFET & $W(\mu \mathrm{m})$ & $L(\mu \mathrm{m})$ \\
\hline $\mathrm{M}_{1}, \mathrm{M}_{2}$ & 20 & 1.8 \\
$\mathrm{M}_{3}, \mathrm{M}_{4}, \mathrm{M}_{5}, \mathrm{M}_{6}, \mathrm{M}_{9}$, & 43 & 0.5 \\
$\mathrm{M}_{10}$ & 43 & 1.25 \\
$\mathrm{M}_{7}, \mathrm{M}_{8}, \mathrm{M}_{11}, \mathrm{M}_{12}$ & & \\
\hline
\end{tabular}

not remain as efficient and practically viable due to the requirement of an excessive number of OTAs.

In comparison, the new circuits are free from above mentioned deficiencies of the circuits presented earlier in [3-9].

\section{Concluding Remarks}

Five new current-mode electronically controllable
OTA-C sinusoidal oscillators have been presented. Like the recently proposed circuits of [1], the proposed circuits also employ only three MO-OTAs and grounded capacitors as preferred for IC fabrication [10] and [11]. However, by contrast to the circuits presented in [1] both of which require three capacitors and hence are non-canonic, the proposed circuits require only two capacitors and hence, are canonic. All the proposed circuits enjoy the feature of independent controllability of oscillation frequency and condition of oscillation, which is not available in one of the circuits presented in [1]. The new circuits are also free from the drawbacks of the circuits presented earlier in [3-9]. Also, all the proposed circuits provide quadrature outputs as an additional feature not available in the circuits of [1]. The active and passivesensitivities of all the circuits are very low. The workability 


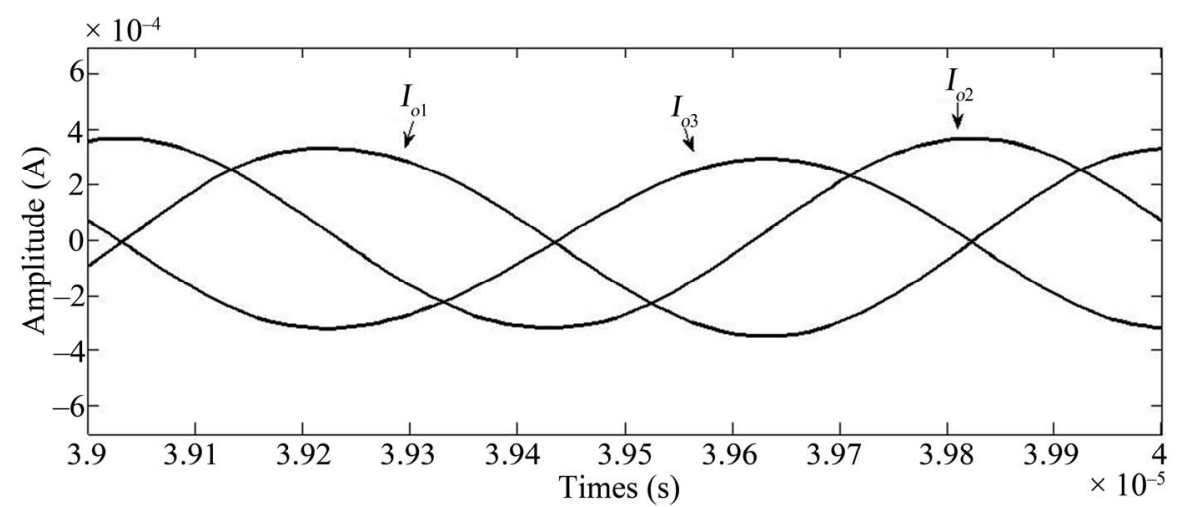

(a)

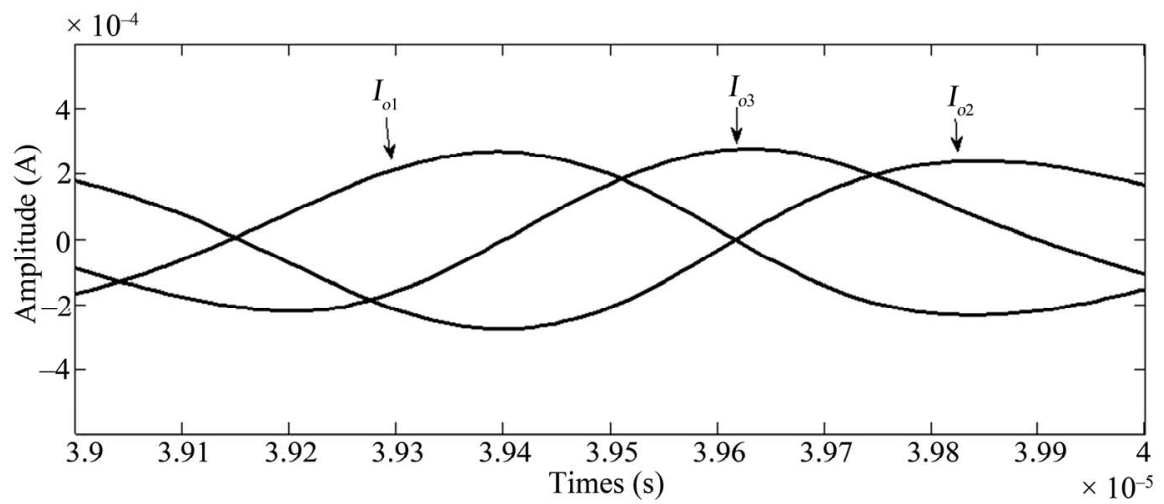

(b)

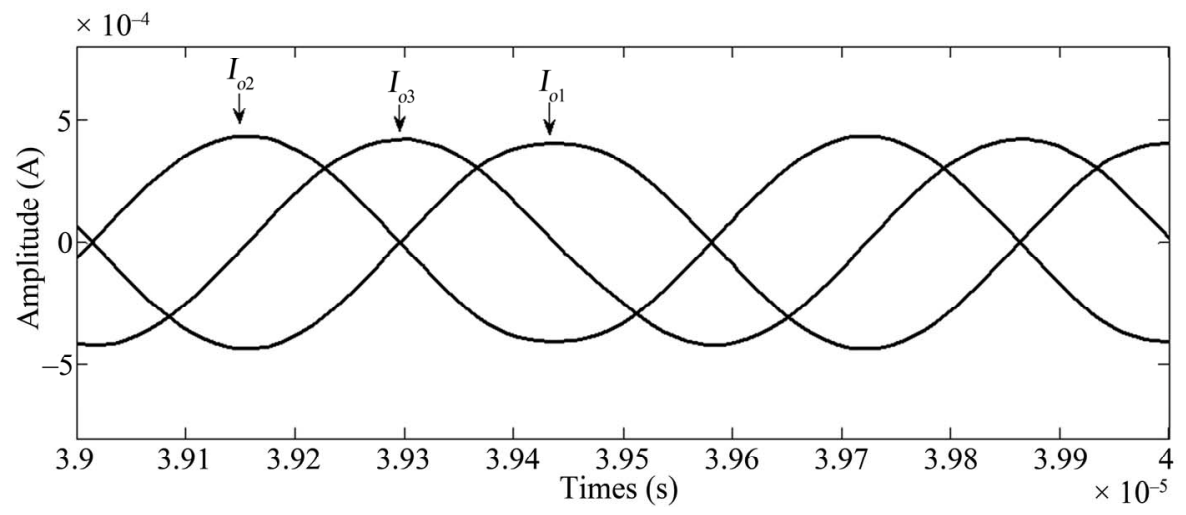

(c)

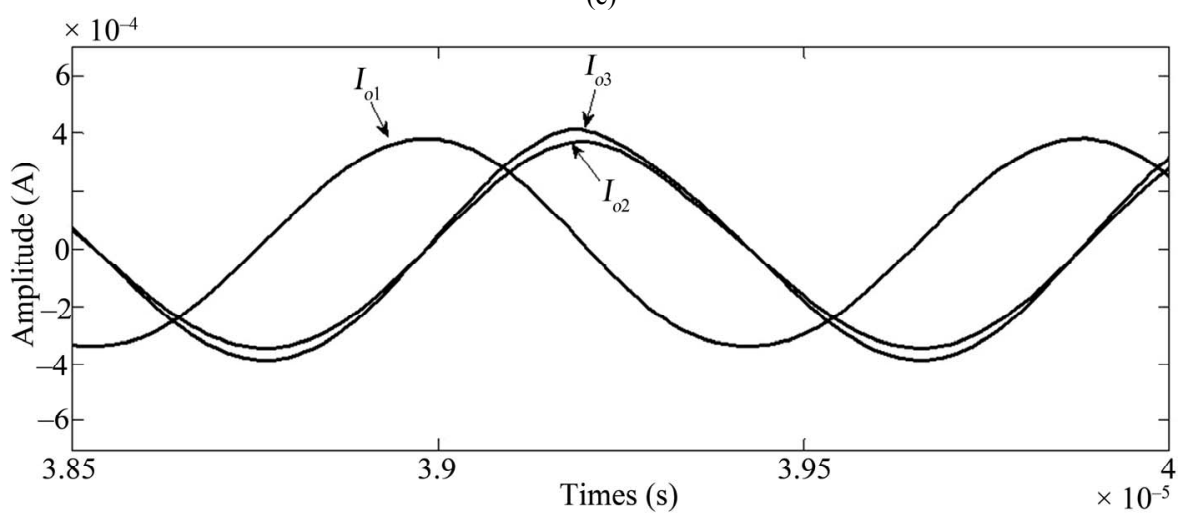

(d) 


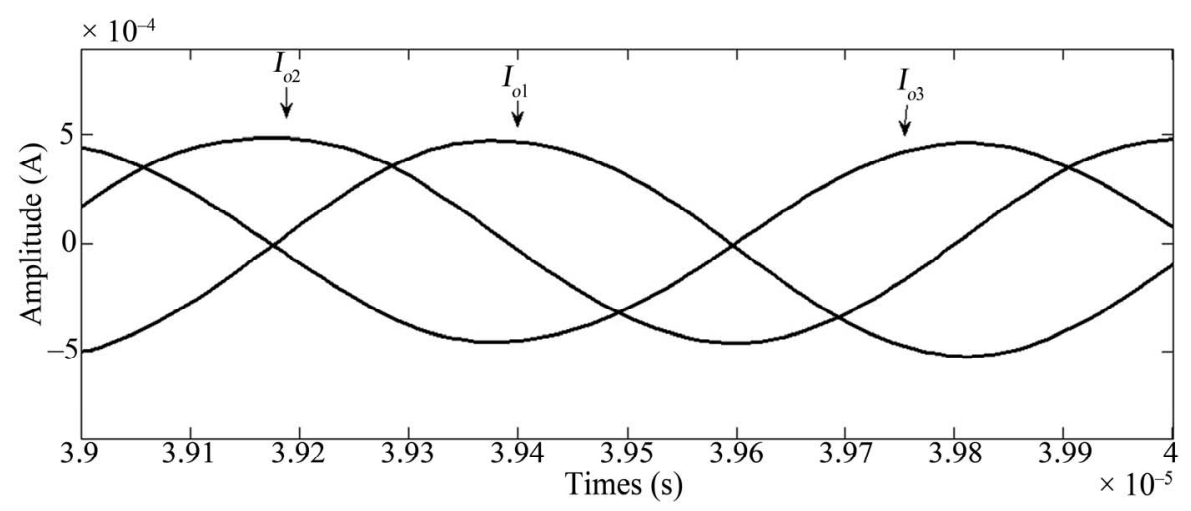

(e)

Figure 3. Output waveforms of (a) circuit 1 (b) circuit 2 (c) circuit 3 (d) circuit 4 (e) circuit 5.

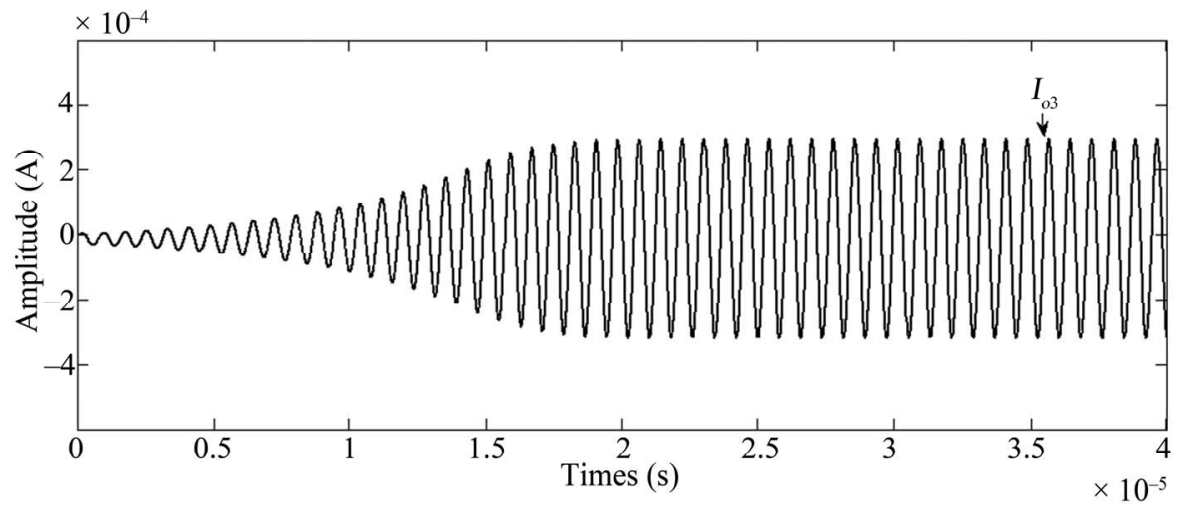

(a)

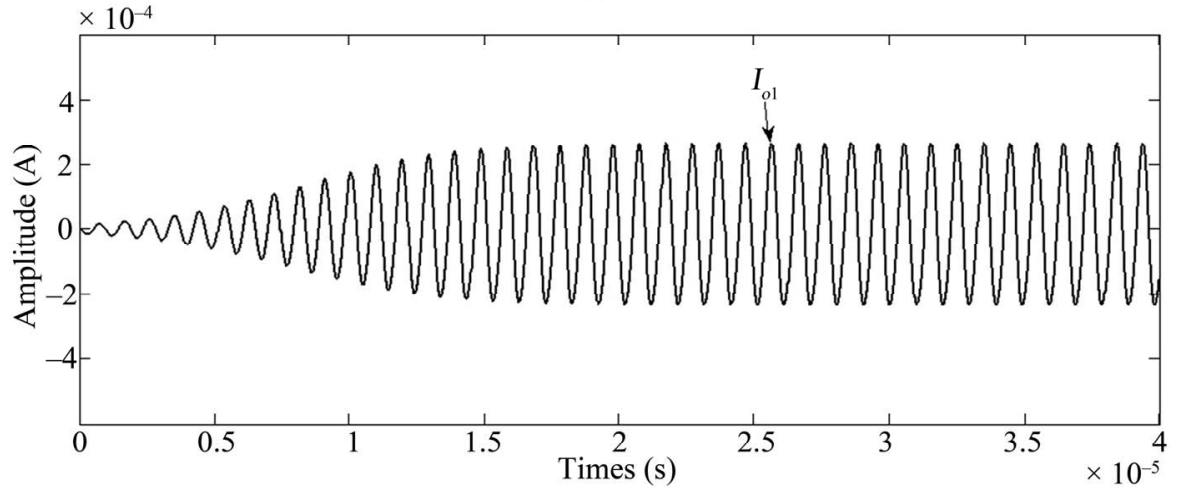

(b)

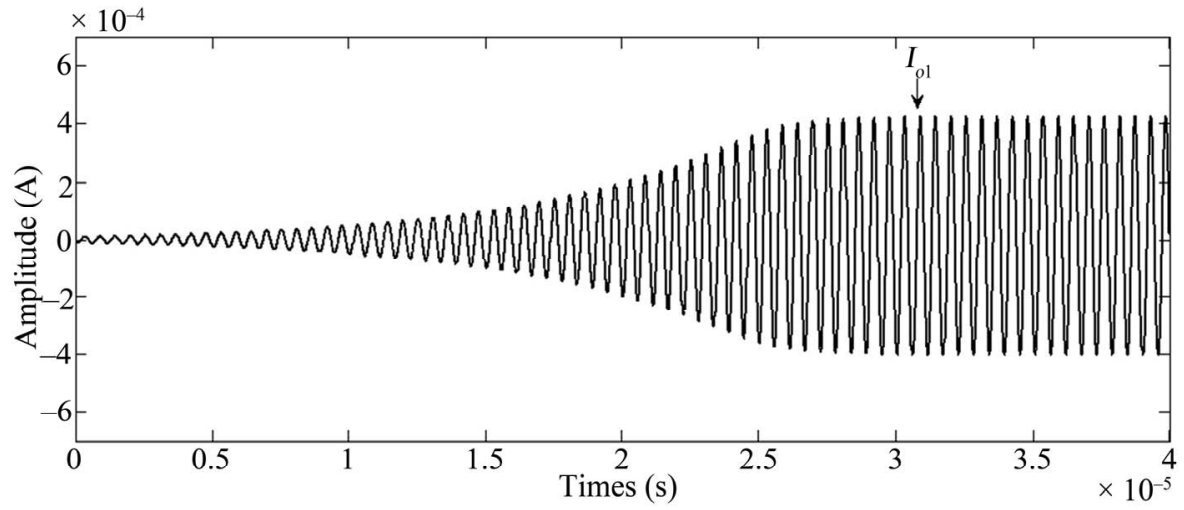

(c) 


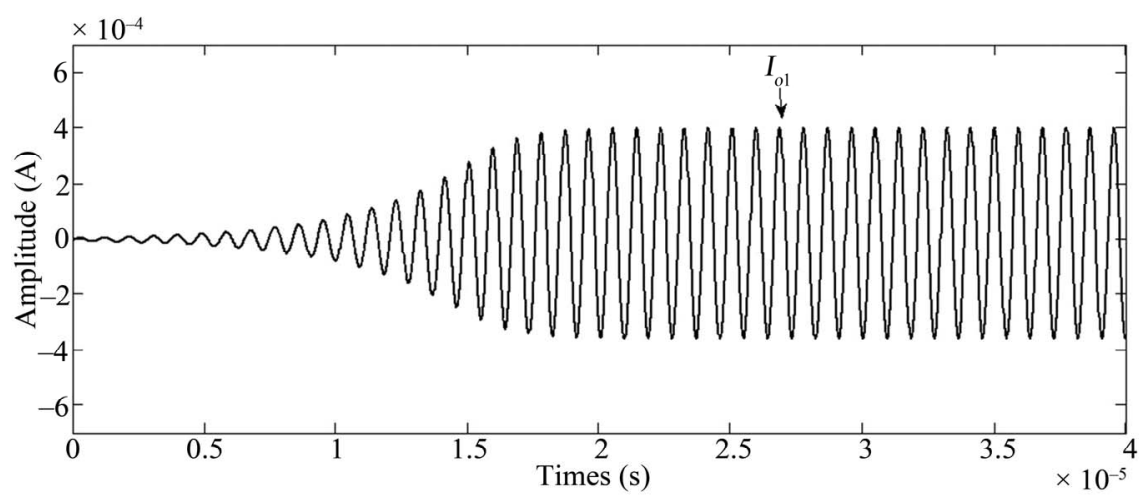

(d)

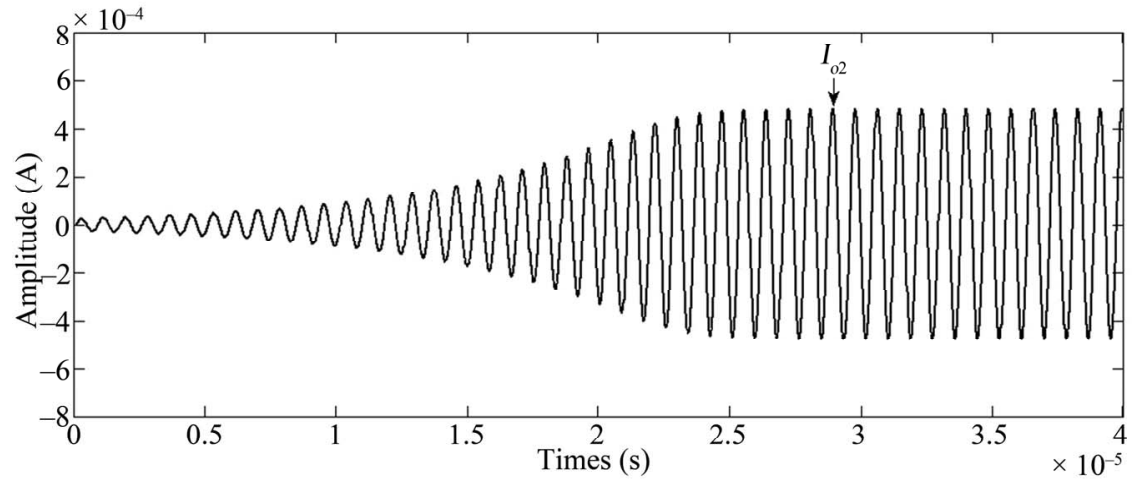

(e)

Figure 4. Output transient of (a) circuit 1 (b) circuit 2 (c) circuit 3 (d) circuit 4 (e) circuit 5.

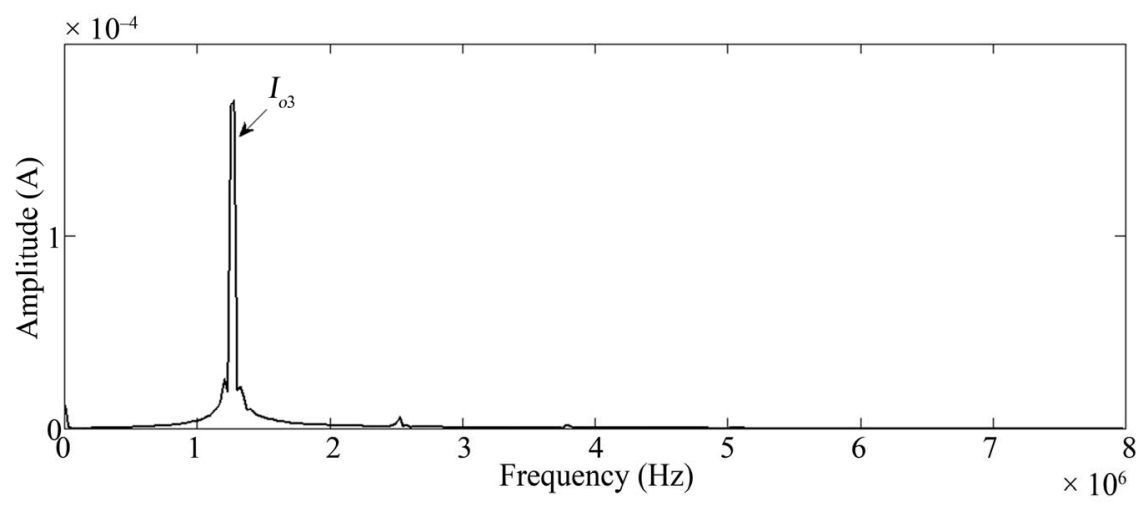

(a)

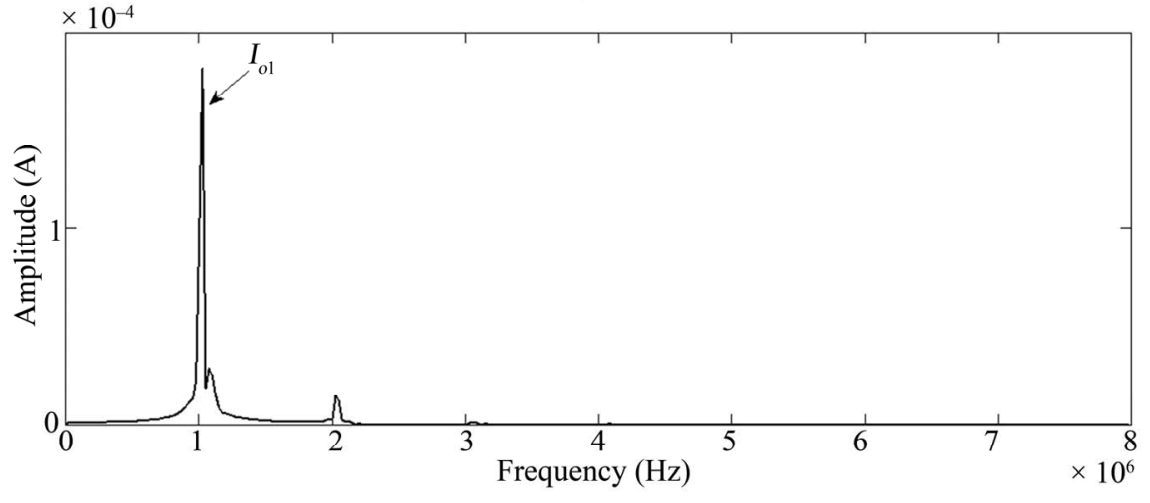

(b) 


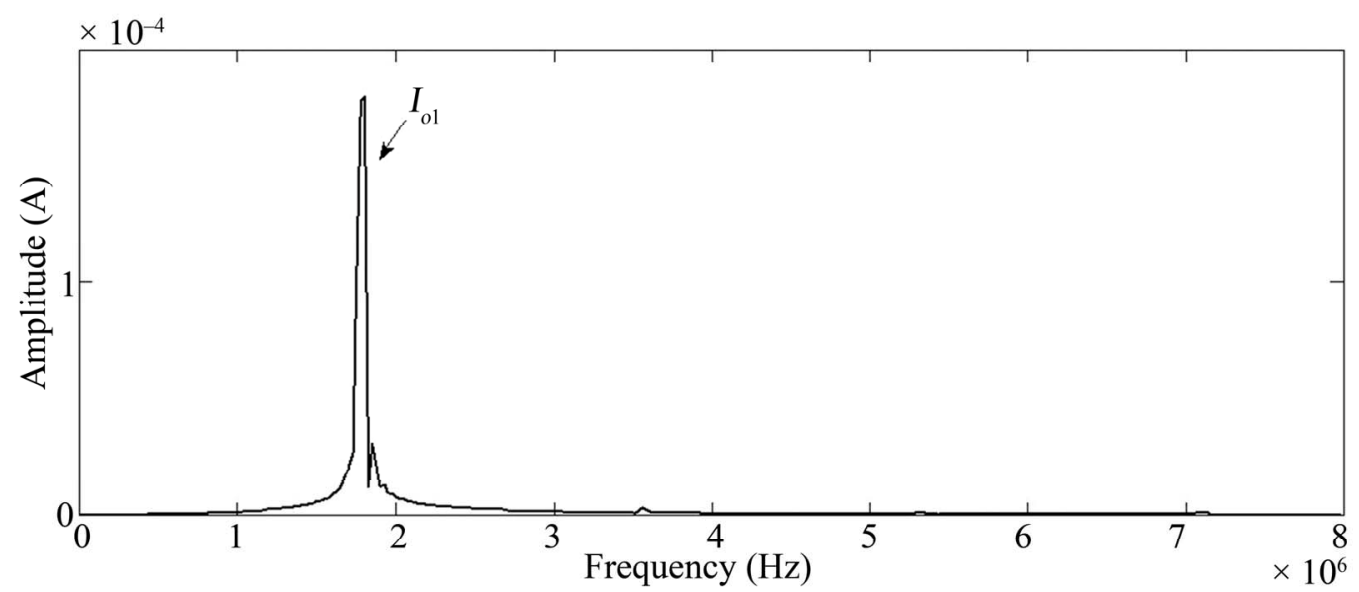

(c)

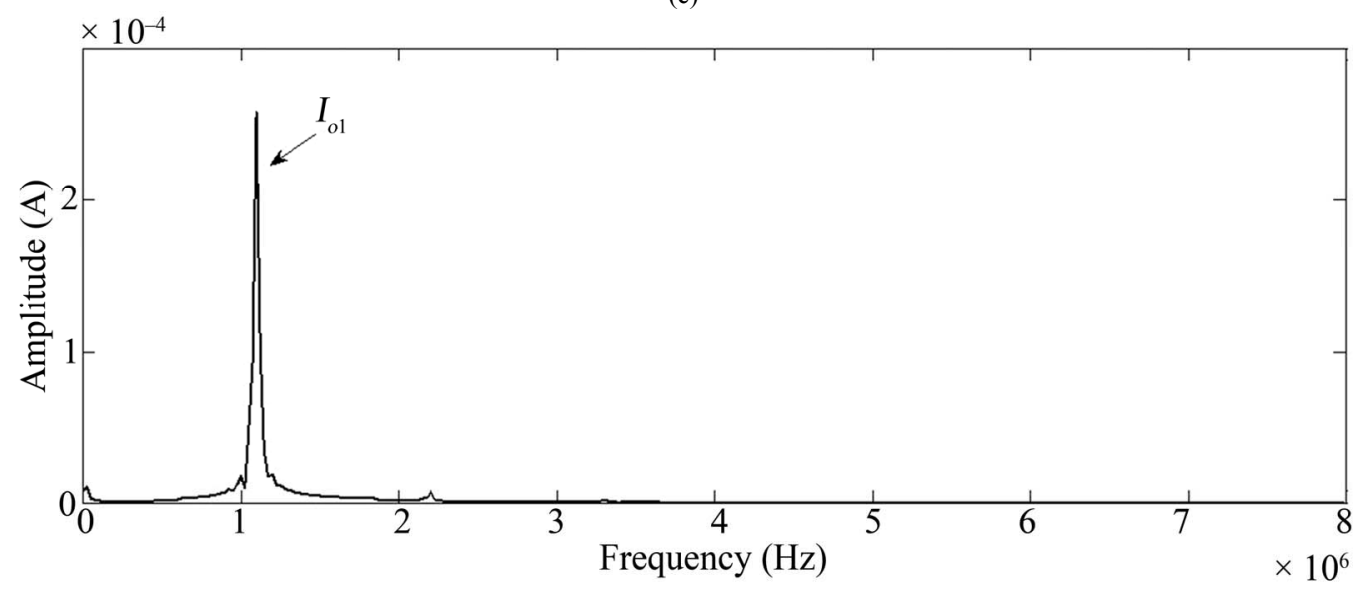

(d)

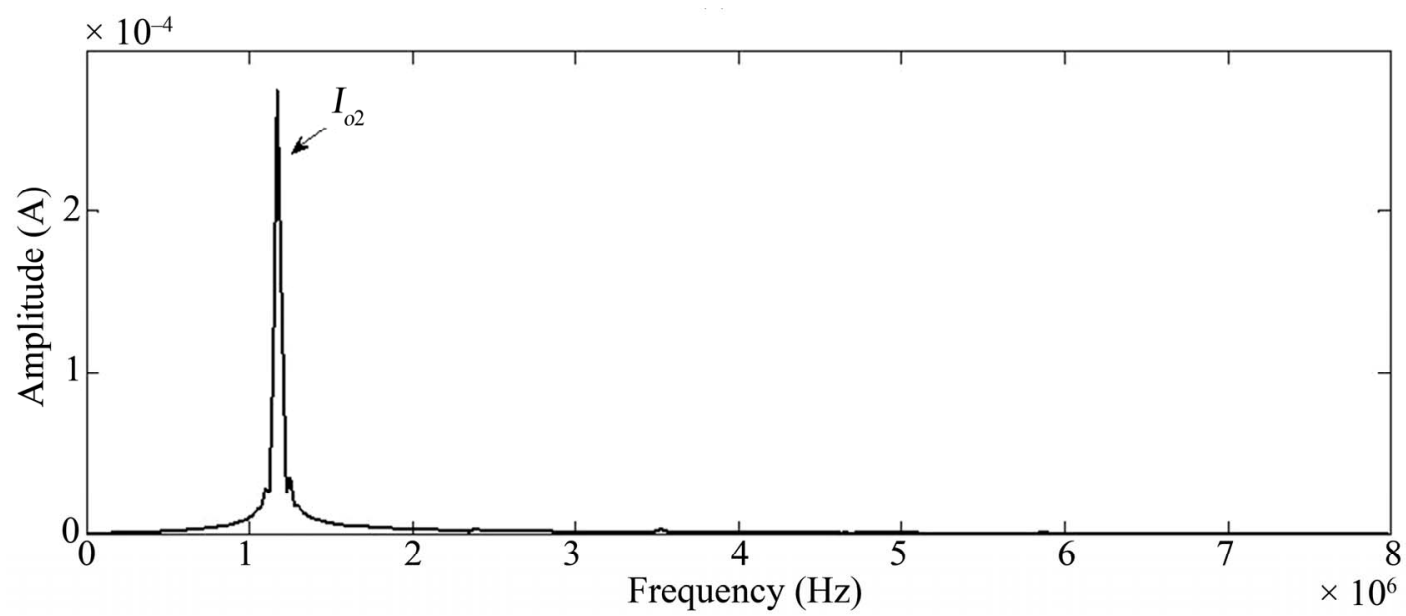

(e)

Figure 5. Frequency spectrum of (a) circuit 1 (b) circuit 2 (c) circuit 3 (d) circuit 4 (e) circuit 5.

of the proposed circuits has been demonstrated by SPICE simulation results.

The transconductance of an OTA is temperature dependent this calls for appropriate temperature compensation for which numbers of schemes are known in the literature [12-14]. However, the study of modified versions of the proposed circuits incorporating temperature compensation would require considerable additional work; therefore, it was considered to be outside the scope of present work. Lastly, it may be mentioned that the 


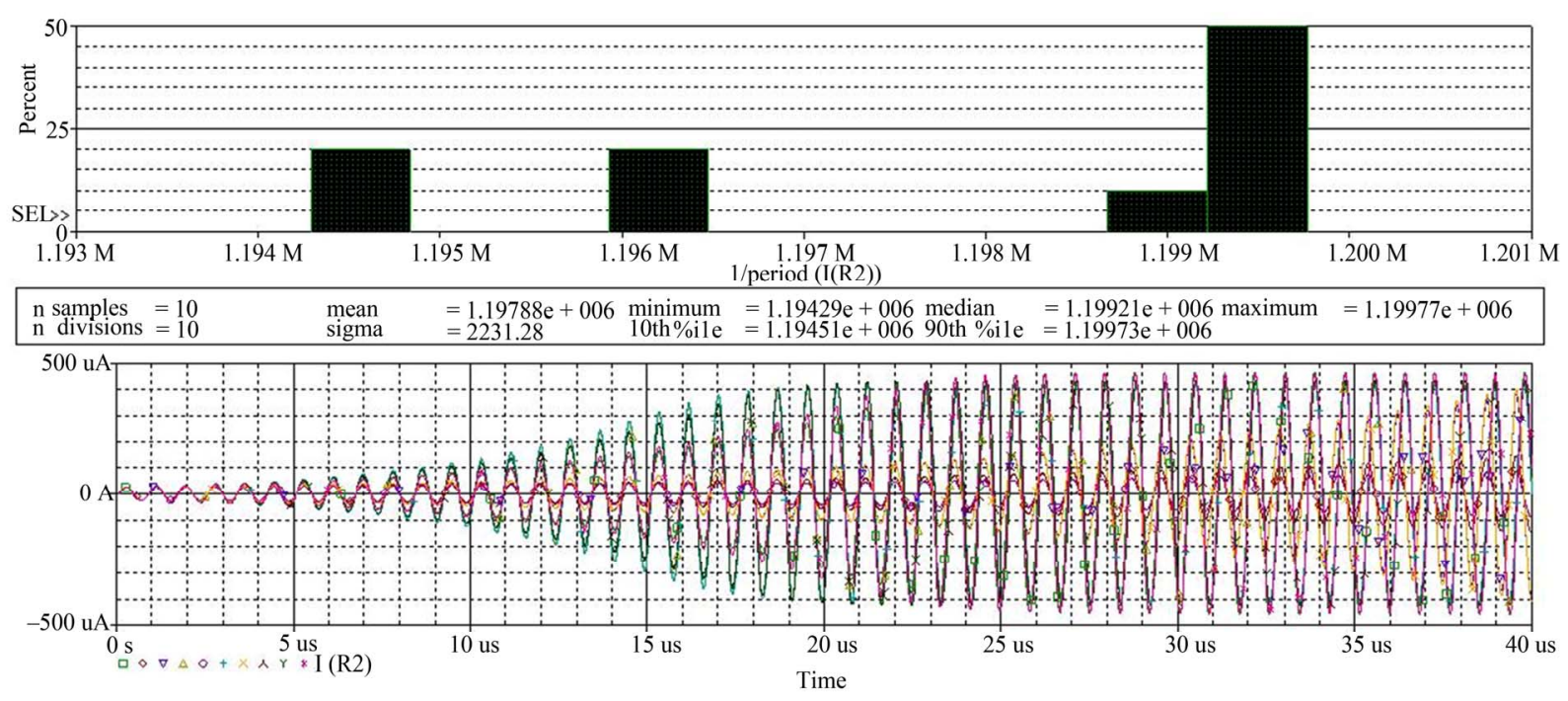

Figure 6. Result of the Monte-Carlo Simulation of oscillator circuit (5) of Figure 1.

Table 3. The values of the capacitors and transconductances for various oscillators.

\begin{tabular}{|c|c|c|c|c|c|c|c|c|c|c|c|}
\hline $\begin{array}{c}\text { Circuit } \\
\text { No. }\end{array}$ & $\begin{array}{c}g_{m 1} \\
(\mathrm{~mA} / \mathrm{V})\end{array}$ & $\begin{array}{c}I_{b 1} \\
(\mathrm{~mA})\end{array}$ & $\begin{array}{c}g_{m 2} \\
(\mathrm{~mA} / \mathrm{V})\end{array}$ & $\begin{array}{c}I_{b 2} \\
(\mathrm{~mA})\end{array}$ & $\begin{array}{c}g_{m 3} \\
(\mathrm{~mA} / \mathrm{V})\end{array}$ & $\begin{array}{c}I_{b 3} \\
(\mathrm{~mA})\end{array}$ & $\begin{array}{c}C_{1} \\
(\mathrm{nF})\end{array}$ & $\begin{array}{c}C_{2} \\
(\mathrm{nF})\end{array}$ & $\begin{array}{c}F_{\text {Theoretical }} \\
(\mathrm{MHz})\end{array}$ & $\begin{array}{c}F_{\text {Practical }} \\
(\mathrm{MHz})\end{array}$ & THD \\
\hline 1 & 0.7954 & 2.8 & 0.7954 & 2.8 & 0.712 & 1.47 & 0.1 & 0.1 & 1.265918 & 1.277 & $2.6 \%$ \\
\hline 2 & 0.793 & 2.73 & 0.715 & 1.5 & 0.804 & 3.4 & 0.12 & 0.1 & 1.101566 & 1.1803 & $5.2 \%$ \\
\hline 3 & 0.7523 & 1.95 & 0.794 & 2.75 & 0.7718 & 2.26 & 0.07 & 0.07 & 1.732487 & 1.734 & $1.6 \%$ \\
\hline 4 & 0.7954 & 2.8 & 0.7046 & 1.4 & 0.788 & 2.6 & 0.11 & 0.11 & 1.083157 & 1.1514 & $2.3 \%$ \\
\hline 5 & 0.785 & 2.53 & 0.715 & 1.5 & 0.777 & 2.36 & 0.1 & 0.1 & 1.192361 & 1.1996 & $1 \%$ \\
\hline
\end{tabular}

circuits proposed in this paper are inspired by the ideas contained in [15-19].

\section{References}

[1] T. Tsukutani, Y. Sumi and Y. Fukui, "Electronically Controlled Current-Mode Oscillators Using MO-OTAs and Grounded Capacitors," Frequenz, Vol. 60, No. 11-12, 2006, pp. 220-223. doi:10.1515/FREQ.2006.60.11-12.220

[2] W. Tangsrirat, " Current Differencing Transconductance Amplifier-Based Current-Mode Four-Phase Quadrature Oscillator," Indian Journal of Engineering and Material Sciences, Vol. 14, No. 4, 2007, pp. 289-294.

[3] D. V. Kamat, P. V. A. Mohan and K. G. Prabhu, “ Novel First-Order and Second-Order Current-Mode Filters Using Multiple-Output Operational Amplifiers," Circuits Syst Signal Process, Vol. 29, No. 3, 2010, pp. 553-576. doi:10.1007/s00034-010-9163-y

[4] M. T. Abuelma'atti, "New Minimum Componet Electronically Tunable OTA-C Sinusoidal Oscillators," Electronics Letters, Vol. 25, No. 17,1989, pp. 1114-1115. doi:10.1049/el:19890747

[5] M. T. Abuelma'atti and M. H. Khan, "Grounded Capacitor Oscillators Using a Single Operationl Transconductance Amplifier," Active and Passive Electronic
Components, Vol. 19, No. 2, 1996, pp. 91-98.

[6] Y. Tao and J. K. Fidler, "Generation of Second-Order Single-OTA RC Oscillators," IEE Proceedings of Circuits Devices Systems, Vol. 145, No. 4, 1998, pp. 271-277. doi:10.1049/ip-cds:19981872

[7] Y. Tao and J. K. Fidler, "Electronically Tunable Dual-OTA Second-Order Sinusoidal Oscillator/Filters with Non-interacting Controls: A Systematic Synthesis Approach," IEEE Transactions on Circuits Systems I, Vol. 47, No. 2, 2000, pp. 117-129.

[8] V. Singh, "Equivalent Forms of Dual-OTA RC Oscillators with Application to Grounded-Capacitor Oscillators," IEE Proceedings of Circuits Devices Systems, Vol. 153, No. 2, 2006, pp. 95-99. doi:10.1049/ip-cds:20050099

[9] V. Singh, "Equivalent Forms of Single-Operational Transconductance Amplifier RC Oscillators with Application to Grounded-Capacitor Oscillators," IET Circuits Devices Systems, Vol. 4, No. 2, 2010, pp. 123-130. doi:10.1049/iet-cds.2009.0146

[10] B. Bhushan and R. W. Newcomb, "Grounding of Capacitors in Integrated Circuits," Electronics Letters, Vol. 3, No. 4, 1967, pp.148-149. doi:10.1049/el:19670114

[11] R. Senani, "Realization of a Class of Analog Signal Processing/Signal Generation Circuits: Novel Configura- 
tion Using Current-Feedback Op-Amps," Frequenz, Vol. 52, No. 9-10, 1998, pp. 196-206.

doi:10.1515/FREQ.1998.52.9-10.196

[12] H. S. Malvar and M. Luettgen, "Temperature Compensation of OTA-Based Filters and Multipliers," Electronics Letters, Vol. 23, No. 17, 1987, pp. 890-891. doi:10.1049/el:19870629

[13] W.-S. Chung, H.-W. Cha and K.-H. Kim, "TemperatureStable VCO Based on Operational Transconductance Amplifiers," Electronics Letters, Vol. 26, No. 22, 1990, pp. 1900-1901. doi:10.1049/el:19901223

[14] C. A. Karybakas, C. Kosmatopoulos and T. Laopoulos, "Improved Temperature Compensation of OTAs," Electronics Letters, Vol. 28, No. 8, 1992, pp. 763-764. doi:10.1049/el:19920482

[15] R. Senani, M. P. Tripathi, D. R. Bhaskar and A. K. Banerjee, "Systematic Generation of OTA-C Sinusoidal Oscillators," Electronics Letters, Vol. 26, No. 18, 1990, pp. 1457-1459. doi:10.1049/el:19900935

[16] D. R. Bhaskar, M. P. Tripathi and R. Senani, "A Class of Three-OTA-Two-Capacitor Oscillators with Non-interacting Controls," International Journal of Electronics, Vol. 74, No. 3, 1993, pp. 459-463. doi:10.1080/00207219308925849

[17] D. R. Bhaskar, M. P. Tripathi and R. Senani, "Systematic Derivation of All Possible Canonic OTA-C Sinusoidal Oscillators," Journal of the Franklin Institute, Vol. 330, No. 5, 1993, pp. 885-903. doi:10.1016/0016-0032(93)90083-7

[18] R. Senani, "New Electronically Tunable OTA-C Sinusoidal Oscillator," Electronics Letters, Vol. 25, No. 4, 1989, pp. 286-287. doi:10.1049/el:19890199

[19] M. T. Abuelma'atti, "Two New Integrable Active-C OTA-Based Voltage (Current) Controlled Oscillators," International Journal of Electronics, Vol. 66, No. 1, 1989, pp. 135-138. doi:10.1080/00207218908925369 